\title{
STATISTICAL ANALYSIS OF WIND SPEED AND EVALUATION OF WIND POWER DENSITY FOR COLABA, MUMBAI
}

\author{
Felix A. Francis
}

P.G. Student, Department of Civil Engineering,

Pillai HOC College of Engineering and Technology, Rasayani, Dist. Raigad, Maharashtra, India,

\section{Dr. Tejaswini D. Nalamutt}

Professor, Department of Civil Engineering,

Pillai HOC College of Engineering and Technology, Rasayani. Dist. Raigad, Maharashtra, India

\begin{abstract}
The fuel energy resources around the globe are declining at a faster rate. The greenhouse gases emitted in the process of harnessing energy from the non-renewable resources such as coal, fossil-fuel and radioactive substances cause the global warming and there is a danger of climate change. All these factors compel the researchers to explore renewable sources for power generation. Wind is a renewable resource, which is available naturally and is practically inexhaustible. In this study, the hourly wind data collected between the years 2013 to 2015 is evaluated. The wind data at the height of $11 \mathrm{~m}$ was obtained from a wind station at the Indian Meteorological Department, Colaba (Mumbai, India). The highest monthly wind speed measured was $5.11 \mathrm{~m} / \mathrm{s}$ and the yearly average was found to be $2.72 \mathrm{~m} / \mathrm{s}$. various distribution functions were statistically analyzed and it was observed that the Two-parameter Weibull distribution gives the best fit to the actual data. The mean wind power density was $73.013 \mathrm{~W} / \mathrm{m} 2$. The maximum wind speeds can be observed between the months of June and September. The wind data analysis shows that if a domestic wind turbine is installed at this site, it will generate enough energy for power saving. This paper aims to promote the growth of small wind power plant in a developing country like India.
\end{abstract}

Keywords: Wind Speed, Wind Rose, Weibull parameters, Power density

Cite this Article:, Felix A. Francis and Dr. Tejaswini D. Nalamutt, Statistical Analysis of Wind Speed and Evaluation of Wind Power Density for Colaba, Mumbai, International Journal of Advanced Research in Engineering and Technology, 10(1), 2019, pp 20-33.

http://iaeme.com/Home/issue/IJARET?Volume=10\&Issue $=1$ 


\section{INTRODUCTION}

Industrial revolution has constantly increased mankind's demand for energy. Most of the energy generated is harnessed from a non-renewable source. Most of these non-renewable sources are fossil fuels [1]. These energy sources which have a limited availability, when harnessed results in degradation of the environment. Hence to reduce the negative impact of the fossil fuels, scientists were forced to focus on cleaner energy sources which are easily available and environmental friendly [2]. The energy sources which do not exhaust when their energy is exploited are known as renewable energy resources [3]. Renewable energy is available in the form of flowing water, waves, wind, sunlight, geothermal energy \& biological processes. Harnessing these natural phenomena for human use requires proper knowledge and technologies. Amongst the mentioned renewable resources, technology for harnessing energy from the solar and wind has seen a vast development in past few years [4].

To balance the global temperature caused by non-uniform heating of the earth's surface, a force is created which push the air masses around. This motion of air masses is known as wind. Wind energy or wind power generation can be described as the process in which the wind is converted to mechanical energy [5]. A device such as wind turbine can be used to convert the kinetic energy of the wind to mechanical energy. This mechanical power can be used to produce electricity by using a generator [6]. The process of harnessing energy from wind is clean, uses little land and there is no emission of any greenhouse gas [7].

The wind power is distributed over a large area on our planet and is available in abundance. Off-shore winds have greater velocity than the winds available near the coasts. The off-shore wind analysis shows that Maharashtra has the maximum wind energy potential after Gujarat [8]. According to the Ministry of New and Renewble Energy (MNRE), the cumulative wind power installed capacity in India at the end of $9^{\text {th }}$ Five Year Plan (FYP) was only $1.7 \mathrm{GW}$ and during $12^{\text {th }}$ FYP more than $15 \mathrm{GW}$ wind capacity is added. The wind installed capacity of India added in each FYP can be explained by the graph given by the MNRE shown in Figure 1. Extraction of power from wind has undoubtedly achieved remarkable improvement over a decade and also significant growth is seen in the operating efficiencies.

Wind Installed Capacity (GW)

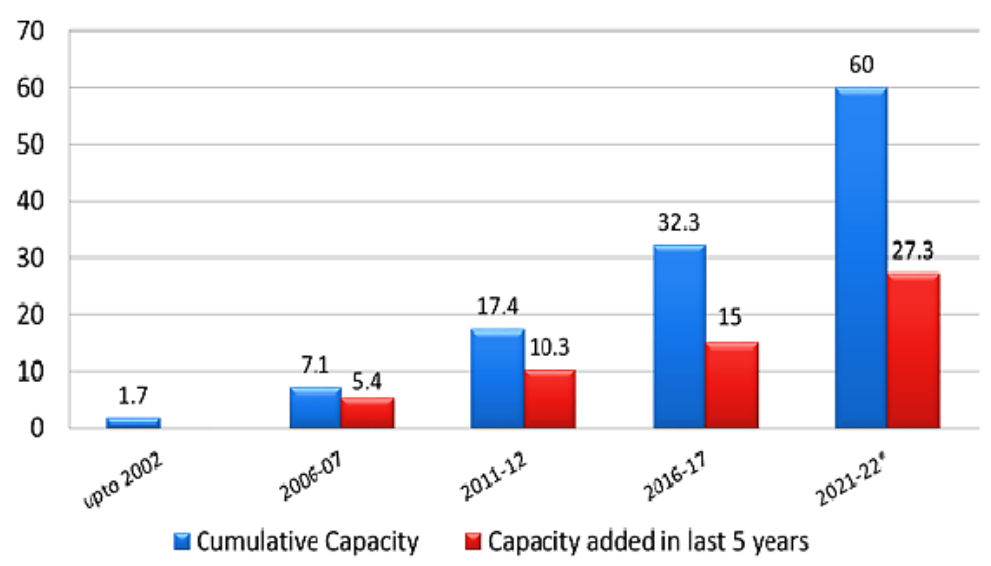

Figure 1 Wind installed capacity of India (URL 1)

To install a standalone small scale power plant for local level, every aspect including the efficiency, economy and environmental impact requires a detailed research [9]. Estimation of the wind energy can be done through proper statistical analysis. It helps to estimate either the energy potential or the wind velocity for the site [10]. Various approaches in studying the wind 
characteristics and estimation of its output have been made. Amongst all the other statistical methods, the Weibull distribution gives the most suitable depiction of the wind characteristics [11]. The two parameter Weibull distribution function with scale parameter (c) and shape parameter (k) is most widely accepted to fit a real data. Graphical method was used to derive the parameters when the computers were not as powerful as they are today as it could be performed manually with negligible calculations. It was observed that when there is a time series format data, the Weibull distribution parameters estimated by the maximum likelihood method is more suitable than the graphical method [12]. The mean annual velocity and the wind energy potential of a site can be estimated by using the Weibull parameters.

The wind data analysis includes the distribution curves, cumulative curves, mean wind speeds and plotting a wind rose diagram [13]. The energy that can be generated from a wind power site will always be less than its estimated theoretical energy potential because of the Betz limit coefficient. The extractable energy due to this capacity factor reduces up to $59.3 \%$ of the total energy available [14]. The wind speed for different elevations for a same site can be obtained by calculating its wind shear coefficient. The wind shear coefficient helps to find the approximate value of the wind speed available at different elevations with respect to an accurate data at a particular height [15]. It is difficult to setup a domestic wind power plant in urban areas as there is no proper wind data available even though the new domestic wind turbines have enormous potential. This leads to increase in the use of polluting energy sources like diesel generators. Significant amount of diesel consumption can be reduced by using a wind-diesel hybrid system power plant [16]. Specific wind data of the site is required for mounting of a wind turbine [7]. Therefore by proper wind data analysis of a selected site it is possible to setup domestic wind power plants in urban areas.

\section{STATISTICAL FUNCTIONS}

Assessment of wind energy potential requires the understanding of wind speed distribution as an elementary step by proper statistical analysis. The economic and technical features for the site can be expediently determined after competently specifying the wind speed distribution. Many researchers have used various probability functions in the study of the distribution of wind speeds. Unremitting attempts have been tried by experts to determine distribution models and obtain the most suitable distribution parameters in order to efficiently evaluate wind speed distribution. From sundry literatures, few of the distribution functions used to study the wind data are described in this section.

\subsection{Normal distribution function}

It is a probability distribution function for the normally mannered distributed wind speed variable and is expressed as the formula given in equation (1) [17];

$$
f(v)=\frac{1}{\sqrt{2 \pi \sigma}} \exp \left(-\frac{(v-\mu)^{2}}{2 \sigma^{2}}\right)
$$

Here wind speed is denoted as $v$, value of $\pi$ is taken as (22/7), standard deviation is denoted as $\sigma$ and mean is denoted as $\mu$.

\subsection{Lognormal distribution function}

It is a probability distribution for the normally distributed logarithm wind speed variable and can be expressed by the formula given in equation (2) $[18,19]$;

$$
f(v)=\frac{1}{\sqrt{2 \pi \sigma} v} \exp \left(-\frac{(\ln (v)-\mu)^{2}}{2 \sigma^{2}}\right)
$$


Statistical Analysis of Wind Speed and Evaluation of Wind Power Density for Colaba, Mumbai

Here wind speed is denoted as $v$, value of $\pi$ is taken as $(22 / 7)$, standard deviation is denoted as $\sigma$ and mean is denoted as $\mu$.

\subsection{Log-logistic distribution function}

It is a probability distribution for the logistic form logarithm of wind speed variable and it is obtained by the formula stated in equation (3) [20];

$$
f(v)=\frac{\left(\frac{\beta}{\alpha}\left(\frac{v}{\alpha}\right)^{\beta-1}\right)}{\left(\left(1+\frac{v}{\alpha}\right)^{\beta}\right)^{2}}
$$

Here wind speed is denoted as $v$, scale parameter is taken as $\alpha$ and shape parameter is denoted as $\beta$.

\subsection{Rayleigh distribution function}

In a special case of shape factor $(\mathrm{k}=2)$ in the Weibull distribution and is written as the formula given in equation (4) [20, 21];

$$
f(v)=\left(\frac{v}{c^{2}}\right) \exp \left(-\frac{v^{2}}{2 c^{2}}\right)
$$

Here wind speed is denoted as $v$ and scale parameter is denoted as $c$.

\subsection{Weibull distribution function}

This distribution is most widely accepted for the study of wind data. It can be expressed as the formula stated in equation (5) [22, 23];

$$
f(v)=\left(\frac{k}{c}\right)\left(\frac{v}{c}\right)^{k-1} \exp \left[-\left(\frac{v}{c}\right)^{k}\right]
$$

Here wind speed is denoted as $v$, scale parameter is taken as $c$ and shape parameter is denoted as $k$.

The suitability value for Weibull distribution is maximum compared to all other distributions [17] and hence among all the other probability distribution function which help in determining the distribution of wind speed frequency, Weibull distribution prove to give a better fit and is most commonly used [24].

\section{METHODOLOGY}

This study was conducted to observe the wind characteristics at a specified location. Evaluation of wind energy potential for a particular site can be done with proper knowledge. Figure 2 shows the flowchart of the methodology used for this study which was adopted after studying the works of various researchers 
Felix A. Francis and Dr. Tejaswini D. Nalamutt

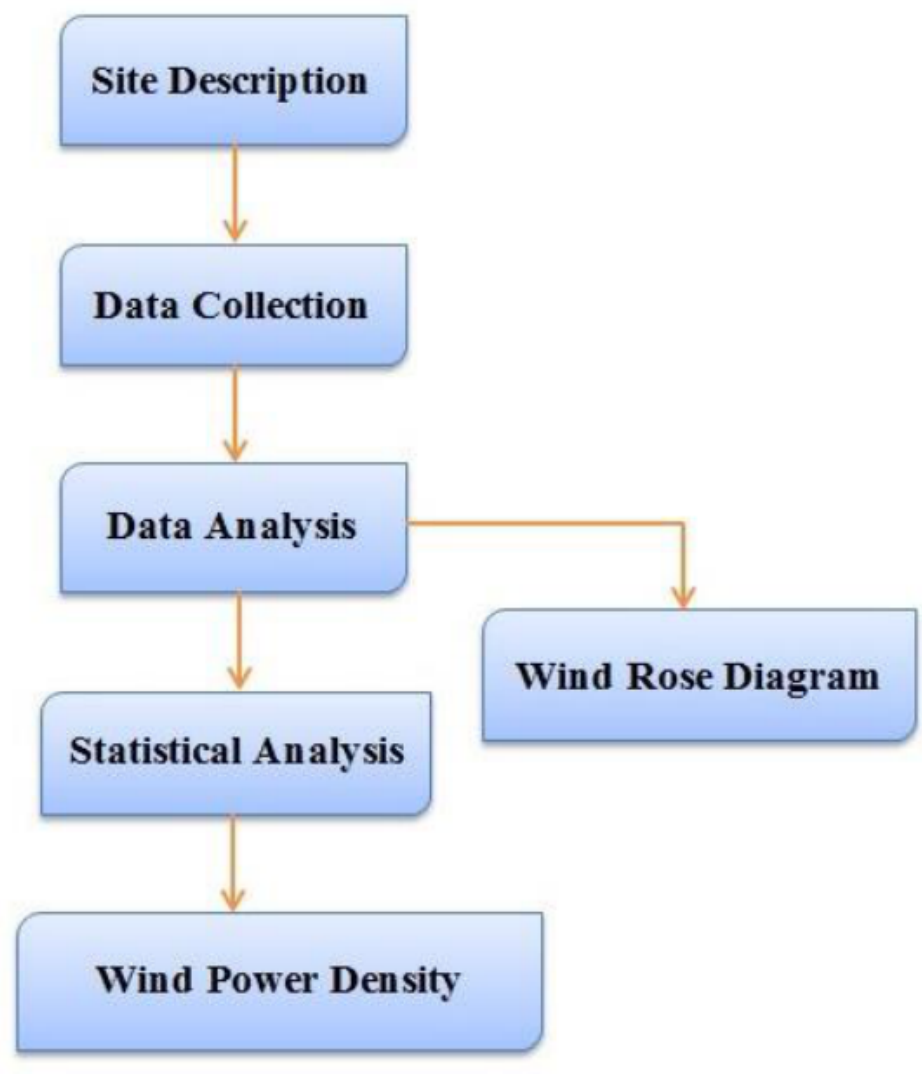

Figure 2 Flowchart of the methodology used for this study

\subsection{Site Description and data collection}

To evaluate the wind potential over any location, the basic factor is to have a proper knowledge of the nature of wind speed. The theoretical estimation of the wind power depends on the cubed value of the wind velocity and hence the accuracy of this analysis is pivotal [25]. The local meteorological department monitors the wind speed and directions. In this research work, the data related to wind speed is collected by authentication of the Indian Meteorological Department (IMD), Vile Parle for the wind station situated at the Indian Meteorological Department (IMD), Colaba (Mumbai, India). The wind data of three years (2013 to 2015) was collected in the hourly series format. Table 1 shows the details of the co-ordinates of the wind station and Figure 3 shows the location map.

Table 1 Wind station details

\begin{tabular}{|c|c|c|}
\hline Sr. No. & Description & Values \\
\hline 1. & Latitude & $18^{\circ} 53^{\prime} 51.72^{\prime \prime} \mathrm{N}$ \\
\hline 2. & Longitude & $72^{\circ} 48^{\prime} 47.52^{\prime \prime} \mathrm{E}$ \\
\hline 3. & Altitude (AGL) & 11 meters \\
\hline
\end{tabular}


Statistical Analysis of Wind Speed and Evaluation of Wind Power Density for Colaba, Mumbai

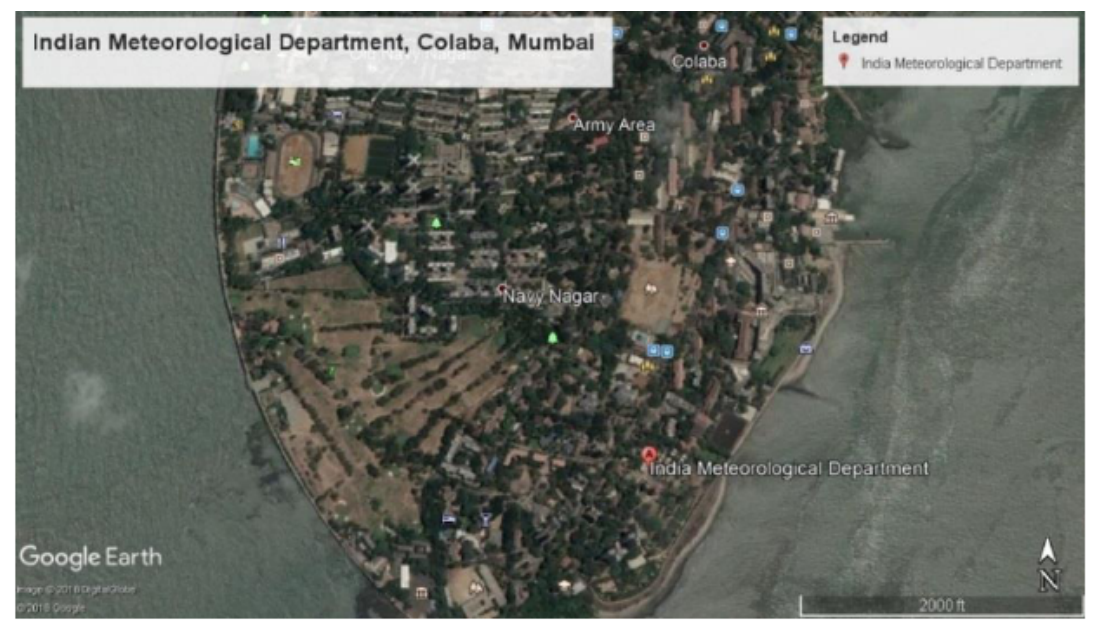

Figure 3 Location of IMD, Colaba, Mumbai

\subsection{Wind rose diagram}

Wind rose can be described as a graphic tool that gives a compact view about the distribution of direction and speed of the wind for a particular station. Emanating from zero at the center, the concentric circles represent a different frequency increasing at the outer circles [24]. Wind roses normally use 16 fundamental directions, each at angle of $22.5^{\circ}$.

\subsection{Distribution functions}

The distribution function helps in understanding the type of data and hence various distribution functions like Normal, Lognormal, Log-logistic, Rayleigh and Weibull were tested for the wind data. Values of Log-Likelihood, p-value \& Akaike's Information Criterion (AIC) shown in Table 2 for each distribution function, helps in determining the distribution with best fit. The Weibull distribution gives the highest values for Log-Likelihood and p-value and the least value for AIC when compared to the other distribution functions.

Table 2 Comparison of various probability distributions

\begin{tabular}{|c|c|c|c|c|c|c|}
\hline Distribution & Parameter & Value & Mean & $\begin{array}{c}\text { Log- } \\
\text { Likelihood }\end{array}$ & $\begin{array}{c}\text { p- } \\
\text { value }\end{array}$ & AIC \\
\hline Rayleigh & $\mathrm{c}$ & 2.60709 & 2.91727 & -65861 & - & 236890 \\
\hline \multirow{2}{*}{ Normal } & $\mu$ & 2.72114 & \multirow{2}{*}{2.72114} & \multirow[t]{2}{*}{-61250} & \multirow{2}{*}{ 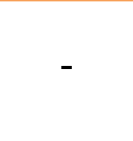 } & \multirow[t]{2}{*}{122503} \\
\hline & $\sigma$ & 2.48864 & & & & \\
\hline \multirow{2}{*}{ Log-logistic } & $\mu$ & 0.539187 & \multirow{2}{*}{5.46939} & \multirow[t]{2}{*}{-55098} & \multirow{2}{*}{$\begin{array}{c}< \\
0.005\end{array}$} & \multirow[t]{2}{*}{110201} \\
\hline & $\sigma$ & 0.740054 & & & & \\
\hline \multirow{2}{*}{ Lognormal } & $\mu$ & 0.410359 & \multirow{2}{*}{3.42892} & \multirow[t]{2}{*}{-54604} & \multirow{2}{*}{ - } & \multirow[t]{2}{*}{109212} \\
\hline & $\sigma$ & 1.2821 & & & & \\
\hline \multirow{2}{*}{ Weibull } & $\mathrm{c}$ & 2.72614 & \multirow{2}{*}{2.72018} & \multirow[t]{2}{*}{-52580} & \multirow{2}{*}{$<0.01$} & \multirow[t]{2}{*}{105165} \\
\hline & $\mathrm{k}$ & 1.00523 & & & & \\
\hline
\end{tabular}




\subsection{Mean wind speed}

The wind characteristics can be studied with the help of statistical analysis of the wind speed data. The mean wind speed of a data set can be easily calculated with the help of shape and scale parameter of Weibull distribution. The wind power density of a location can be further calculated with the help of average wind speed. The relation between the average wind speed $\left(\mathrm{V}_{\mathrm{m}}\right)$ and shape parameter $(\mathrm{k})$ and scale parameter $(\mathrm{c})$ of the Weibull distribution is expressed as the formula given in equation (6) [14].

$$
v_{m=c \Gamma}\left(1+\frac{1}{k}\right)
$$

Here the mean wind speed is denoted by $v_{m}$, the Weibull shape and scale parameters are denoted by $k$ and $c$ respectively and the gamma function is denoted by $г$.

\subsection{Wind power density}

The annual energy (W) available at a site upon swept area $\left(\mathrm{m}^{2}\right)$ of the wind turbine i.e. Watts per square meter $\left(\mathrm{W} / \mathrm{m}^{2}\right)$ can be termed as the Wind Power Density (WPD) of that site. The Weibull parameters can be used to evaluate the wind power density by using the formula given in equation (7) [26].

$$
W P D=\frac{1}{2} \rho c^{3} \Gamma\left(1+\frac{3}{k}\right)
$$

Here WPD stands for Wind power density, air density is given as $\rho$ and $c$ and $k$ are Weibull scale and shape parameters respectively.

\section{RESULTS AND DISCUSSION}

A tremendous increase in usage of renewable energy source for energy generation has been observed over a decade. Thus for efficient use of a wind turbine, it is necessary to understand and study the wind energy properly. Enhancing the conception of wind energy potential and improving the efficiency of selected site by opting for the most suitable wind turbine is the main objective of the study. Characteristics of wind are studied of Colaba region in Mumbai city and the potential for wind power are explored. The hourly wind speed and direction data between the years 2013 and 2015 have been collected from the Indian Meteorological Department wind monitoring station at Colaba, Mumbai. After manually copying the three year wind data, the data was organized into yearly, seasonally, monthly and hourly wind speeds for this site.

Predicting the wind flow direction is of great importance while planning the installation of a horizontal axis wind turbine to select the direction in which the turbine shall be facing. It can be said from Figure 4 that the maximum frequency of the wind in the Colaba region was observed to be from the western, north-northwestern, west-northwestern and westsouthwestern. 
Statistical Analysis of Wind Speed and Evaluation of Wind Power Density for Colaba, Mumbai

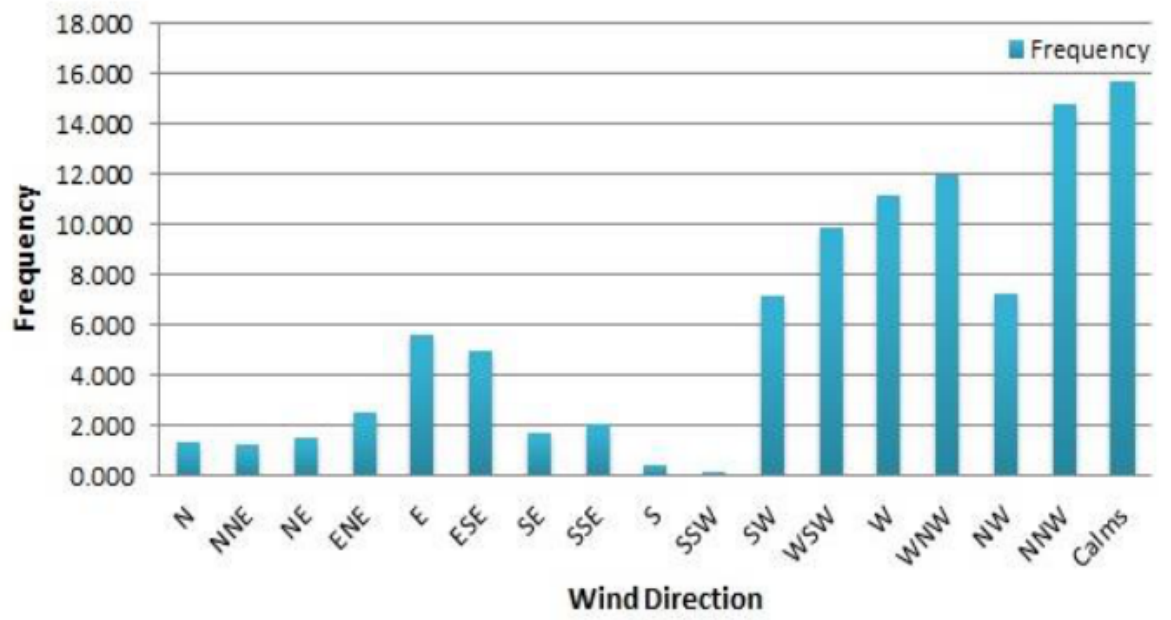

Figure 4 Wind frequency from 16 cardinal directions

Figure 5 shows the wind rose diagram based on the three year data Colaba and also shows the nature of wind and wind distribution over Colaba region that is obtained by exporting the wind rose diagram to Google Earth. This was an expected outcome as Colaba can be considered as a coastal area with the winds blowing from the Arabian Sea from the west. Therefore we can say that the area for which the investigation is carried observes the variation in wind blowing between the north-northwest and south-west south directions.
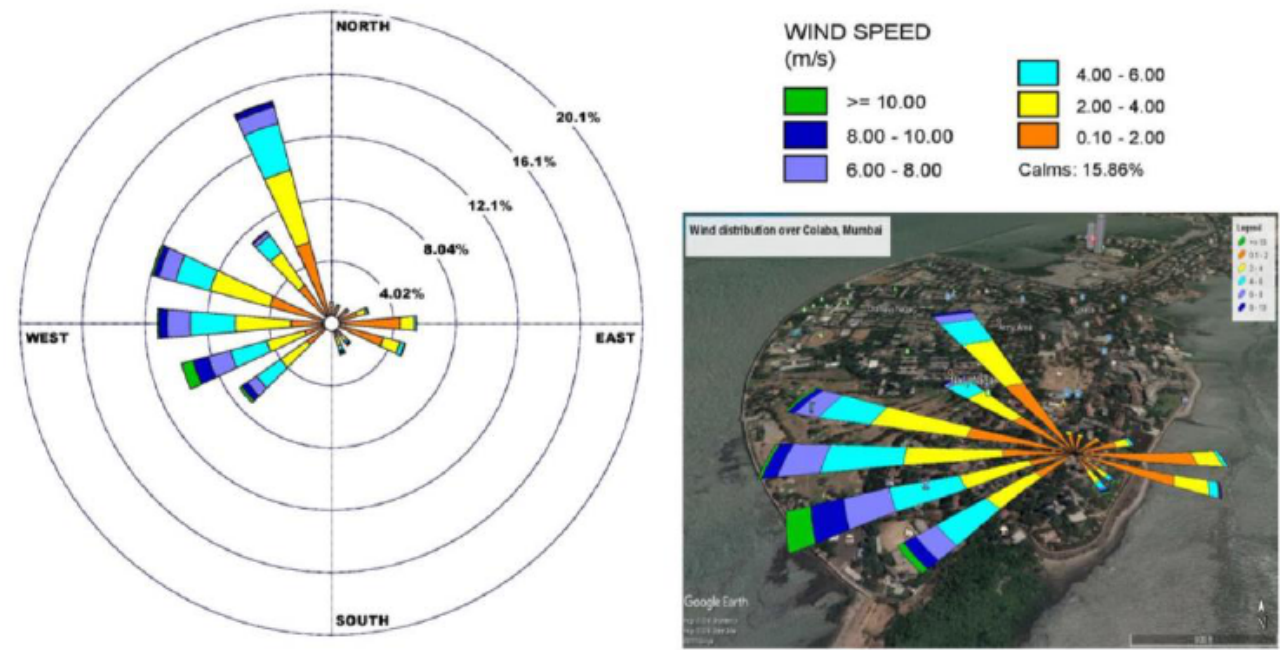

Figure 5. Wind rose diagram and wind distribution over Colaba 2013-15

Probability density function is commonly used to determine any distribution in a period of time. Hourly wind speed distribution at Colaba for the time period of three years was established using probability density function. Probability functions like Rayleigh, Log-normal, Normal, Log-logistic and Weibull distribution functions were applied and tested for the wind data. 
Felix A. Francis and Dr. Tejaswini D. Nalamutt

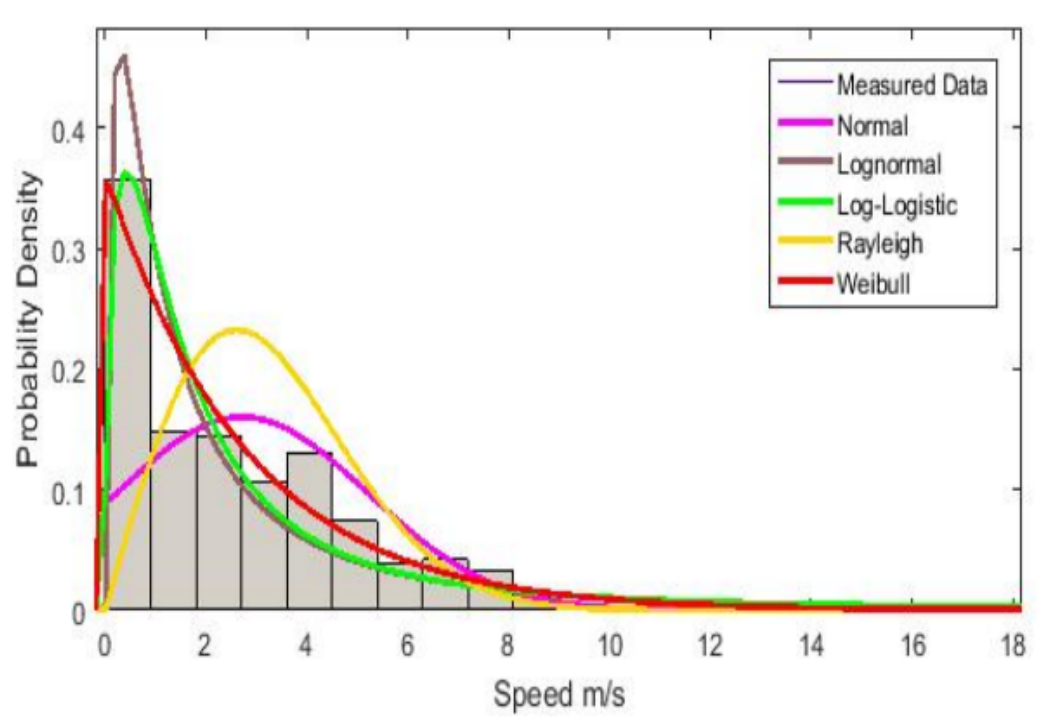

Figure 6 Wind speed probability density distribution

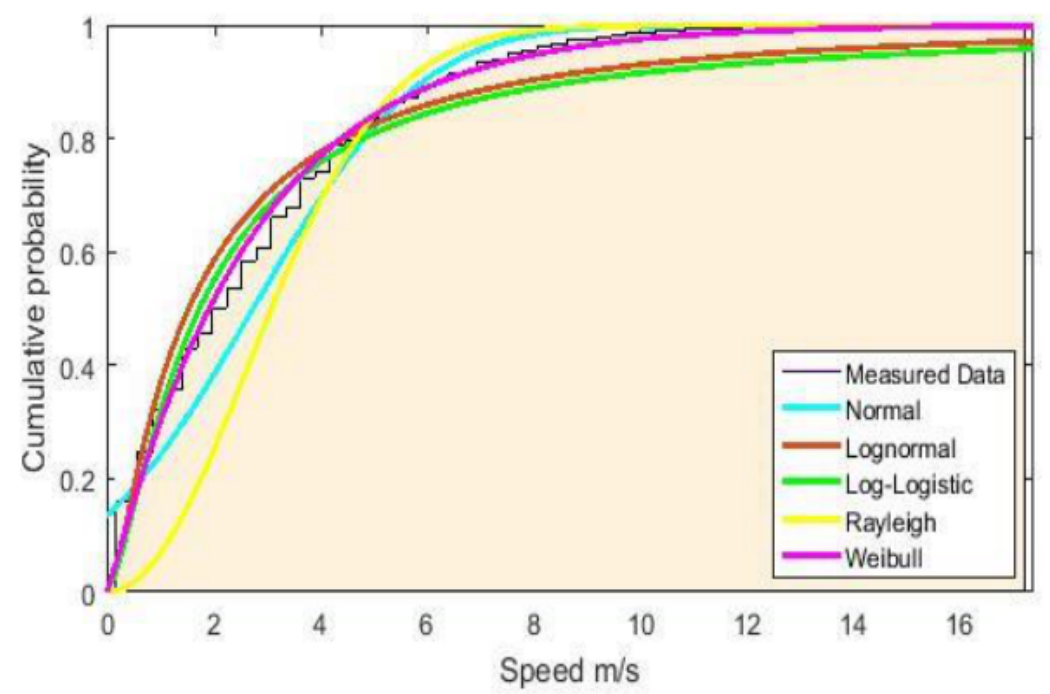

Figure 7 Wind speed cummulative probability distribution

The Normal and Log-normal distribution parameters $\mu$ and $\sigma$ were found to be $2.721 \&$ 2.489 and $0.410 \& 1.282$ respectively giving a mean speed of $3.429 \mathrm{~m} / \mathrm{s}$. The Log-logistic distribution parameters $\mu$ and $\sigma$ showed the values 0.540 and 0.740 respectively and the mean wind speed obtained was $5.469 \mathrm{~m} / \mathrm{s}$. The Rayleigh distribution's scale parameter (c) was observed to be 2.607 giving a mean wind speed of $3.267 \mathrm{~m} / \mathrm{s}$. The Weibull distribution when applied to the wind data, gave the scale parameter (c) as 2.726 and shape parameter (k) as 1.005 which gives the mean speed of $2.720 \mathrm{~m} / \mathrm{s}$. It can be observed from Figure 6 that amongst all the other distribution curves, the Weibull distribution curve fits the actual data more accurately. The cumulative probability curve also favors the Weibull distribution as seen in Figure 7 and hence all the further analysis is based on the Weibull distribution. 
Statistical Analysis of Wind Speed and Evaluation of Wind Power Density for Colaba, Mumbai

Table 3 Weibull parameters for monthly data

\begin{tabular}{|c|c|c|c|}
\hline \multirow{2}{*}{ Months } & \multicolumn{2}{|c|}{ Weibull } & $\begin{array}{l}\text { Mean } \\
\text { Wind } \\
\text { Speed }\end{array}$ \\
\hline & Scale (c) & Shape (k) & $v_{m}$ \\
\hline January & 1.59612 & 1.03767 & 1.572 \\
\hline February & 2.82427 & 1.03251 & 2.788 \\
\hline March & 2.01206 & 1.04412 & 1.978 \\
\hline April & 3.21968 & 1.04078 & 3.168 \\
\hline May & 2.20805 & 1.08892 & 2.138 \\
\hline June & 5.21463 & 1.48128 & 4.715 \\
\hline July & 5.76834 & 2.32667 & 5.111 \\
\hline August & 4.76888 & 1.38956 & 4.352 \\
\hline September & 2.22993 & 1.12087 & 2.139 \\
\hline October & 2.64234 & 0.99710 & 2.646 \\
\hline November & 1.3329 & 1.05172 & 1.307 \\
\hline December & 1.26844 & 1.0135 & 1.261 \\
\hline & & & \\
\hline
\end{tabular}

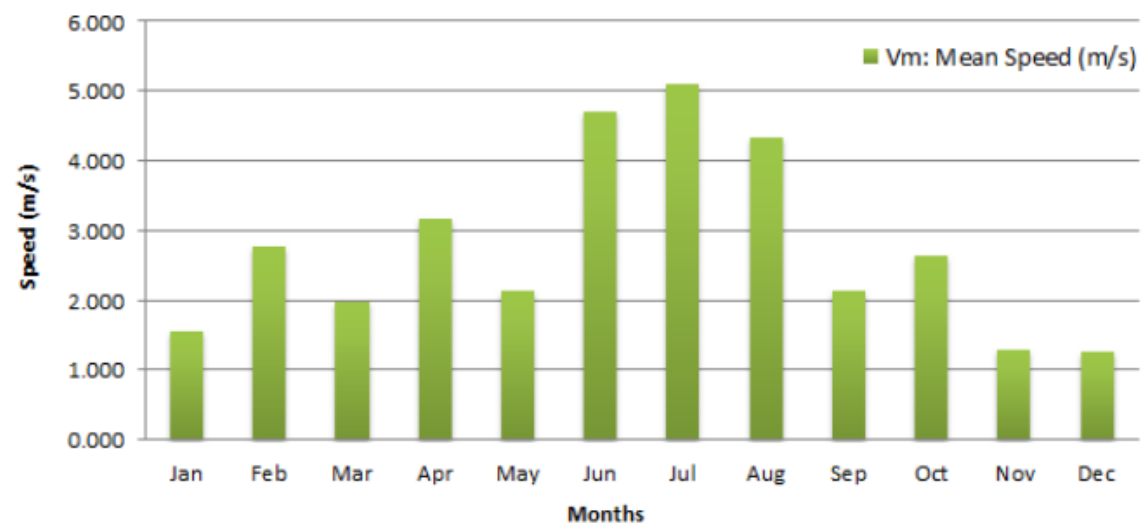

Figure 8 Monthly speed variation

The monthly wind data analysis helps us to estimate the power output for each month so that optimal usage of the wind power plant can be done. This mostly helps where there is a hybrid wind-solar power plant. Table 3 shows the values of monthly Weibull parameters and the variations in the wind speed for each month is represented in Figure 8. The best wind speeds are available from the month of April till August. The maximum average wind velocity of 5.11 $\mathrm{m} / \mathrm{s}$ was observed in the month of July. 
Felix A. Francis and Dr. Tejaswini D. Nalamutt

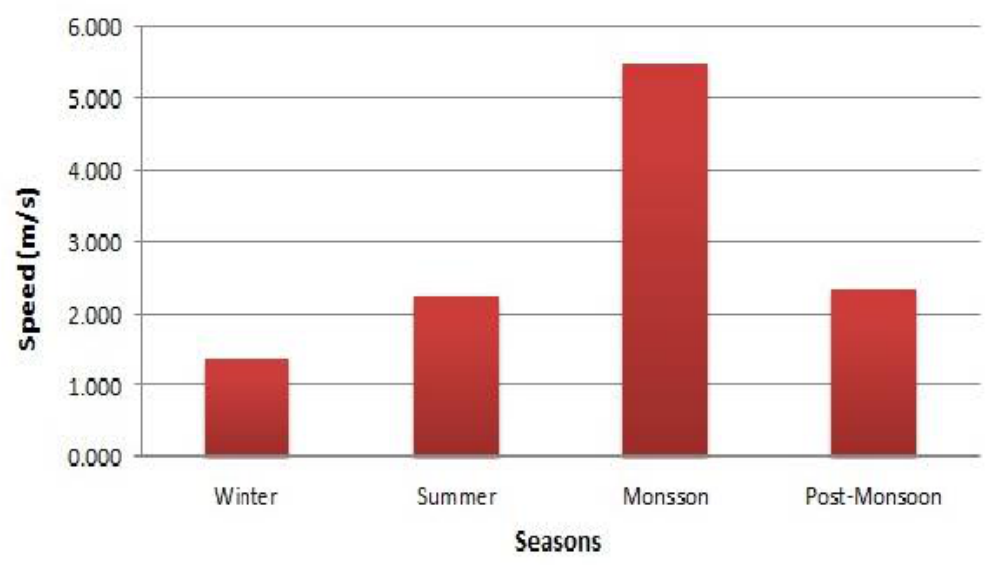

Figure 9 Seasonal speed variation

According to the Indian Meteorological Department (IMD), India observes four seasons which are winter, summer, monsoon and post-monsoon. As mentioned earlier for a hybrid wind-solar power plant, this type of analysis helps to make the optimum use of the plant by properly distributing the loading from each source. It can be said from Figure 9 that the maximum wind speeds were observed during the monsoon season when the solar power plant is not able to generate enough power due to the rains and cloudy weather. The minimum wind speeds were observed during the winter and summer season. The Weibull parameters for the different season were computed and the observed wind speed was maximum $(5.48 \mathrm{~m} / \mathrm{s})$ for the monsoon season while the summer, winter and post-monsoon seasons showed wind speeds less than $2.5 \mathrm{~m} / \mathrm{s}$.

Wind is not a consistent energy source and hence a lot of variations are observed not only monthly or seasonally but also hourly. Figure 10 shows the hourly wind speed variation of the collected wind data. After studying the hourly wind variations it can be perceived that the wind speeds are less and steady from midnight till the morning hours up to 8:00 and gradually increases till the afternoon time around 15:00 and then decreases till 22:00 and is steady again till midnight. Considering the wind velocity of $3 \mathrm{~m} / \mathrm{s}$ and above to generate electricity $[5,24]$, good wind speeds are observed between the times 12:00 to 20:00 in a day. The maximum energy potential at this site in day can be expected during the afternoon till evening period.

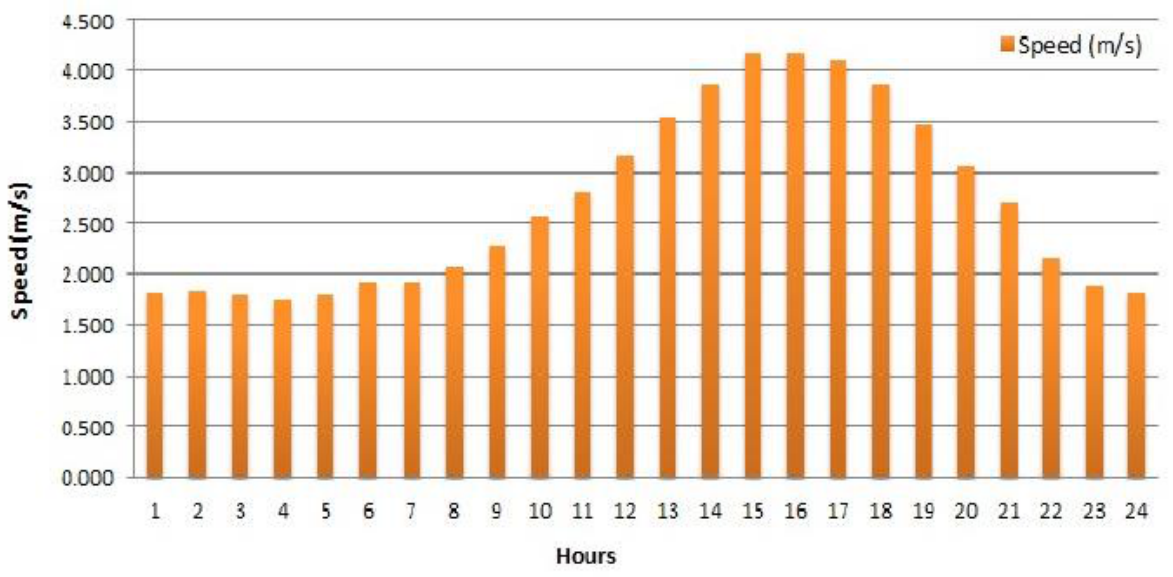

Figure 10 Hourly wind speed variations 


\section{Statistical Analysis of Wind Speed and Evaluation of Wind Power Density for Colaba,}

Mumbai

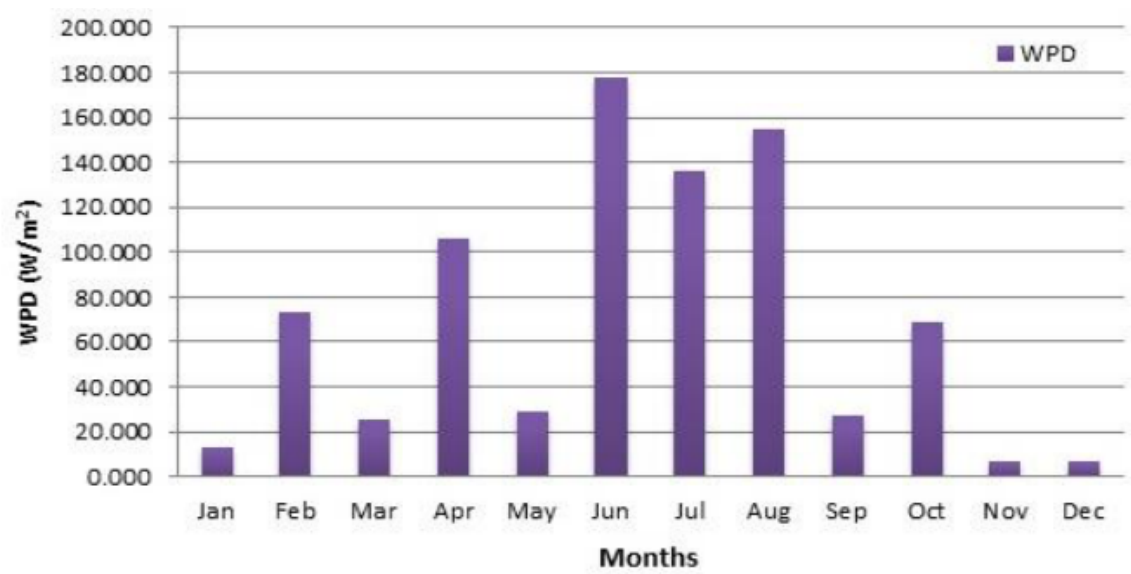

Figure 11 Monthly Wind Power Density

The monthly WPD of Colaba is shown in Figure 11 and it can be observed that the maximum values are obtained between the months of June \& August. The maximum WPD of $177.824 \mathrm{~W} / \mathrm{m}^{2}$ was observed in the month of June. Comparison of Fig. 8 and Fig. 11 shows the dependence of WPD on the wind speed. Another factor that affects the WPD of a site is the air density which in this study was taken as $1.225 \mathrm{~kg} / \mathrm{m}^{3}$ which is stated by the International Standard Atmosphere (ISA). The overall WPD for Colaba between the years 2013 to 2015 is found to be $73.013 \mathrm{~W} / \mathrm{m}^{2}$.

\section{CONCLUSION}

In the present world, energy sources that are renewable are more emphasized. One of the few renewable energy sources available in abundance to mankind is wind. A proper understanding of the wind characteristics is necessary to harness its energy. In this study, wind characteristic of Colaba (Mumbai, India) was systematically investigated. Among the various distribution functions, Weibull distribution function curve was found to be closely matching the wind data. In the monthly analysis, good wind speeds were observed between June and August with the maximum $(5.11 \mathrm{~m} / \mathrm{s})$ during the month of July. The Weibull shape and scale parameter were calculated for the three years hourly data with $\mathrm{k}=1.005 \& \mathrm{c}=2.726$ respectively. The average wind velocity was observed to be $2.72 \mathrm{~m} / \mathrm{s}$ and the WPD calculated was $73.013 \mathrm{~W} / \mathrm{m}^{2}$. Analysis of the wind data shows that this site is has enough potential for electricity generation by driving a small (domestic) wind turbine for standalone purpose.

\section{REFERENCES}

[1] Levent Bilir, Mehmet Imir, Yılser Devrim and Ayhan Albostan , "Seasonal and yearly wind speed distribution and wind power density analysis based on Weibull distribution function", International Journal of Hydrogen Energy, 2015, pp. 1 - 10.

[2] B. Belabes, A. Youcefi, O. Guerri, M. Djamai and A. Kaabeche, "Evaluation of wind energy potential and estimation of cost using wind energy turbines for electricity generation in north of Algeria", Renewable and Sustainable Energy Reviews 51, 2015, pp. 1245 - 1255.

[3] M. A. Baseer, J.P. Meyer, Md. Mahbub Alam and S. Rehman, "Wind speed and power characteristics for Jubailindustrial city, Saudi Arabia", Renewable and Sustainable Energy Reviews 52, 2015, pp. 1193 - 1204.

[4] Ketan R. Aghera and Pratik H. Savasani, "Solar-Wind Hybrid System Generation and Control Using Power Electronics Devices", International Journal of Engineering Development and Research, Vol 2, Issue 3, 2015, pp. 2897 - 2902. 
[5] Ahmed Shata Ahmed, "Wind energy characteristics and wind park installation in Shark ElOuinat, Egypt", Renewable and Sustainable Energy Reviews 82, 2018, pp. 734 - 742.

[6] E. Kavak Akpinar and S. Akpinar, "An assessment on seasonal analysis of wind energy characteristics and wind turbine characteristics", Energy Conversions and Management 46, 2005, pp. $1848-1867$.

[7] Firoz Alam, Abdulkadir Ali, Iftekhar Khan and Saleh Mobin, "Status of power generation by domestic scale wind turbines in Australia", Procedia Engineering 49, 2012, pp. 205 - 212.

[8] Jobil Varghese, Freeda Christy and Katta Venkattaramana, Offshore Wind Energy Potential along Indian Coast. International Journal of Civil Engineering and Technology, 9(7), 2018, pp. 1480-1486.

[9] Ar. Vibha Upadhyaya, Pratheek Sudhakaran, Anjani Kumar Shukla, Shailendra Kumar, Bhavesh Joshi, Application of Small Scale Renewable Energy Techniques in Traditional Buildings of Jaipur. International Journal of Civil Engineering and Technology, 9(2), 2018, pp. 627-643.

[10] H. Saleh, A. Abou El-Azm Aly and S. Abdel-Hady, "Assessment of different methods used to estimate Weibull distribution parameters for wind speed in Zafarana wind farm, Suez Gulf, Egypt", Energy 44, 2012, pp. $710-719$.

[11] Tian Pau Chang, "Estimation of wind energy potential using different probability density functions", Applied Energy 88, 2011, pp. 1848 - 1856.

[12] J. V. Seguro and T. W. Lambert, "Modern estimation of the parameters of the Weibull wind speed distribution for wind energy analysis", Journal of Wind Engineering and Industrial Aerodynamics 85, 2000, pp. $75-84$.

[13] Amir Dabbaghiyan, Farivar Fazelpour, Mohhamadreza Dehghan Abnavi and Marc A. Rosen, "Evaluation of wind energy potential in province of Bushehr, Iran", Renewable and Sustainable Energy Reviews 55, 2016, pp. 455 - 466.

[14] I. Youm, J. Sarr, M. Sall, A. Ndiaye and M. M. Kane, "Analysis of wind data and wind energy potential along the northern coast of Senegal", Rev. Energ. Ren., 2005, Vol 8, pp. $95-108$.

[15] Warit Werapun, Yutthana Tirawanichakul and Jompob Waewask, "Wind Shear Coefficients and their Effect on Energy Production", Energy Procedia 138, 2017, pp. 1061 - 1066.

[16] Neeraj Sharma, Jimmy Kansal and Ashwagosha Ganju, Off-Grid Hybrid Renewable Energy System Sizing For High Altitude Cold Deserts. International Journal of Advanced Research in Engineering and Technology, 4(7), 2013, pp. 101-108.

[17] Jianzhou Wang, Jianming $\mathrm{Hu}$ and Kailiang Ma, "Wind speed probability distribution estimation and wind energy assessment", Renewable and Sustainable Energy Reviews 60, 2016, pp. 881 899.

[18] B. Safari, "Modeling wind speed and wind power distributions in Rwanda", Renew Sustain Energy Rev 15, 2011, pp. $925-35$.

[19] J. Wu, J. Wang and D. Chi, "Wind energy potential assessment for the site of Inner Mongolia in China", Renew Sustain Energy Rev 21, 2013, pp. 215 - 28.

[20] O. Alavi, K. Mohammadi and A. Mostafaeipour, "Evaluating the suitability of wind speed probability distribution models: a case of study of east and southeast parts of Iran", Energy Convers Manag 119, 2016, pp.101 - 8.

[21] S. F. Khahro, K. Tabbassum, A. M. Soomro, L. Dong and X. Liao, "Evaluation of wind power production prospective and Weibull parameter estimation methods for Babaurband, Sindh Pakistan”, Energy Concers Manag 78, 2014, pp. 956 - 67.

[22] K. Sunderland, T. Woolmington, J. Blackledge and M. Conlon, "Small wind turbines in turbulent (urban) environments: a consideration of normal \& Weibull distributions for power predictions", Journal of Wind Engineering and Industrial Aerodynamics 121, 2013, pp. $70-81$.

[23] O. Z. Olaofe and K. A. Folly, "Wind energy analysis based on turbine and developed site power curves: a case study of Darling City", Renew Energy 53, 2013, pp. 306 - 18. 


\section{Mumbai}

[24] A. Allouhi, O. Zamzoum. M. R. Islam, R. Saidur, T. Kousksou, A. Jamil and A. Derouich, "Evaluation of wind energy potential in Morocco's coastal regions", Renewable and Sustainable Energy Reviews 72, 2017, pp. 311 - 324.

[25] Ahmed Ouammi, Hanane Dagdougui, Roberto Sacile and Abdelaziz Mimet, "Monthly and seasonal assessment of wind energy characteristics at four monitored locations in Liguria region (Italy)", Renewable and Sustainable Energy Reviews 14, 2010, pp. 1959 - 1968.

[26] Bharat Kumar Saxena and K. V. S. Rao, "Estimation of wind power density at a wind farm site located in Western Rajasthan region of India", Procedia Technology 24, 2016, pp. $492-498$.

[27] V.Ranganayaki and S.N. Deepa, Optimal Neural Network Models For Wind Speed Prediction. International Journal of Electrical Engineering \& Technology, 6(7), 2015, pp. 01-12

[28] Denny Nugroho Sugianto, Muhammad Zainuri, Alfin Darari, Suripin, Suseno Darsono and Nur Yuwono Wave Height Forecasting Using Measurement Wind Speed Distribution Equation In Java Sea, Indonesia. International Journal of Civil Engineering and Technology, 8(5), 2017, pp. 604-619.

[29] Windaniyati, Iphan F. Radam, The Analysis on the Relationship Between the Noise and the Traffic based on the Distance, Wind Speed and Temperature: A Case on City Road 2/2 UD Type in Banjarmasin. International Journal of Civil Engineering and Technology, 9(8), 2018, pp. $1715-1723$. 